\title{
Effective dose of dexmedetomidine to induce adequate sedation in elderly patients under spinal anesthesia
}

\author{
Ki-Ho Ko ${ }^{1}$, In-Jung Jun², Sangseok Lee ${ }^{2}$, Yunhee Lim², Byunghoon Yoo $^{2}$, \\ and Kye-Min Kim ${ }^{2}$ \\ ${ }^{1}$ Department of Medicine, Jodo Subcenter, Jindo Public Health Center, Jindo, ${ }^{2}$ Department of Anesthesiology and \\ Pain Medicine, Sanggye Paik Hospital, Inje University College of Medicine, Seoul, Korea
}

\begin{abstract}
Background: During sedation with dexmedetomidine, a dose adjustment may be needed based on the invasiveness of the procedure, the patient's general condition, and their age. We aim here to determine the effective dose (ED) of dexmedetomidine to induce an adequate depth of sedation in elderly patients undergoing spinal anesthesia.

Methods: In this study, 47 patients aged 65 years or older, American Society of Anesthesiologists physical status I or II, undergoing spinal anesthesia were included. Patients were randomly allocated into group I, II, III, IV or V according to the dexmedetomidine loading dose of $0.1,0.3,0.5,0.7$ and $1.0 \mu \mathrm{g} / \mathrm{kg}$, respectively. After spinal anesthesia, the assigned loading dose of dexmedetomidine was infused intravenously for 10 minutes, after which infusion was maintained at a rate of 0.3 $\mu \mathrm{g} / \mathrm{kg} / \mathrm{h}$ for the next 10 minutes in all groups. We assessed the depth of sedation with the Ramsay sedation scale every five minutes and measured vital signs and the oxygen saturation. The $\mathrm{ED}_{50}$ and $\mathrm{ED}_{95}$ of dexmedetomidine to obtain adequate sedation (Ramsay sedation score $\geq 3$ ) upon the completion of the loading dose were calculated with logistic regression.

Results: The $\mathrm{ED}_{50}$ and $\mathrm{ED}_{95}$ of dexmedetomidine for adequate sedation were $0.29 \mu \mathrm{g} / \mathrm{kg}$ ( $95 \%$ confidence intervals [CI] $0.14-0.44)$ and $0.86 \mu \mathrm{g} / \mathrm{kg}(95 \% \mathrm{CI} 0.52-1.20)$, respectively. Hypotension was frequent in groups IV, V compared to groups I, II, III (31.6 vs. $3.6 \%, \mathrm{P}=0.013)$.

Conclusions: $\mathrm{ED}_{95}$ of dexmedetomidine loading dose for adequate sedation is $0.86 \mu \mathrm{g} / \mathrm{kg}$. However, dose higher than 0.5 $\mu \mathrm{g} / \mathrm{kg}$ can lead to hemodynamic instability.
\end{abstract}

Key Words: Aged, Dexmedetomidine, Sedation, Spinal anesthesia.

Corresponding author: Kye-Min Kim, M.D., Ph.D.

Department of Anesthesiology and Pain Medicine, Sanggye Paik Hospital, Inje University College of Medicine, 1342, Dongil-ro, Nowon-gu, Seoul 01757 , Korea

Tel: 82-2-950-1168, Fax: 82-2-950-1323

E-mail: kyemin@paik.ac.kr

ORCID: http://orcid.org/0000-0003-1298-7642

This work is a Master's Thesis of Dr. Ki-Ho Ko.

Received: May 20, 2015.

Revised: June 25, 2015.

Accepted: July 7, 2015.

Korean J Anesthesiol 2015 December 68(6): 575-580 http://dx.doi.org/10.4097/kjae.2015.68.6.575

\section{Introduction}

Although regional anesthesia has several advantages over general anesthesia $[1,2]$ awake patients may suffer from anxiety, fear and stress. Dexmedetomidine, a highly selective $\alpha_{2}$ agonist, has been widely used as a sedative in a variety of clinical settings owing to its analgesic properties, minimal respiratory depression and easy arousability $[3,4]$. Recently, it was used for sedation during spinal anesthesia [5], with the benefit of a prolonged duration of sensory and motor block [6].

Hypotension and bradycardia, the most frequent side effects of dexmedetomidine [4], occur in a dose-related manner

(c) This is an open-access article distributed under the terms of the Creative Commons Attribution Non-Commercial License (http://creativecommons.org/ licenses/by-nc/4.0/), which permits unrestricted non-commercial use, distribution, and reproduction in any medium, provided the original work is properly cited. 
$[7,8]$. To avoid these side effects, a dose adjustment is required. For procedural sedation, a loading dose of $0.5-1.0 \mu \mathrm{g} / \mathrm{kg}$ and a maintenance infusion of $0.2-1.0 \mu \mathrm{g} / \mathrm{kg} / \mathrm{h}$ are recommended depending on the invasiveness of the procedure [9]. In elderly patients, due to a higher incidence of bradycardia and hypotension, a reduced dose is recommended [9]. Although there has been some controversy $[10,11]$, it was reported that the clearance of dexmedetomidine decreased with age and the elimination half-life and context-sensitive half-time were prolonged in geriatric patients [12].

Considering that spinal anesthesia itself produces significant sedation $[13,14]$, the required dose of sedatives may be reduced during spinal anesthesia. It has been reported that dexmedetomidine can cause profound sedation, desaturation, and delayed discharge from a post-anesthetic care unit in elderly patients under spinal anesthesia [6].

Although an appropriate dose of dexmedetomidine may be reduced further in elderly patients under spinal anesthesia, there is no information about the dose-response relationship in patients of this age group. In this study, we aim to determine the $\mathrm{ED}_{50}$ and $\mathrm{ED}_{95}$ values of the loading dose of dexmedetomidine to induce an adequate level of sedation in elderly patients under spinal anesthesia.

\section{Materials and Methods}

This study was approved by Institutional Review Board, and written informed consent was obtained from each patient. It was registered with the Clinical Research Information Service. Elderly patients aged 65 years or older, classified as American Society of Anesthesiologists physical status I or II, and scheduled for orthopedic or urologic surgery under spinal anesthesia, were enrolled. Patients with hypovolemia; infection in the low back area; coagulopathy; hypersensitivity to local anesthetics; pre-anesthetic bradycardia (heart rate $[\mathrm{HR}]<60$ beats/min); hepatic disease; renal disease; neurological disease; or a history of chronic medication of sedatives, opioids or analgesics, were not included in the study. Patients who took a sedative or opioid analgesic prior to anesthesia on the day of surgery were also excluded from the study.

The patients did not receive any premedication. For intraoperative monitoring, electrocardiogram, noninvasive blood pressure measurements, and pulse oximetry to measure the peripheral oxygen saturation $\left(\mathrm{SpO}_{2}\right)$ were included. Oxygen at 3 $\mathrm{L} / \mathrm{min}$ was applied via a nasal prong. Before anesthesia, patients were administered 400-500 ml of lactated Ringer's solution for pre-loading. Spinal anesthesia was performed with aseptic techniques in the lateral decubitus position through the L3-4 or L4-5 space in the midline using the Portex ${ }^{\circledR}$ combined spinalepidural set (Smiths Medical, Dublin, OH, USA). An 18-gauge
Tuohy epidural needle was advanced and the epidural space was confirmed by the loss-of-resistance technique with an air-filled syringe. A 27-gauge pencil point spinal needle was introduced into the Tuohy needle to puncture the dura membrane. After confirming the free flow of clear cerebrospinal fluid, 7-10 mg of hyperbaric $0.5 \%$ bupivacaine (Marcaine ${ }^{\circledR}$ Spinal Heavy: $5 \mathrm{mg} /$ $\mathrm{ml}$, Astrazeneca, Södertälje, Sweden) was administered into the subarachnoid space and an epidural catheter was inserted into the epidural space. Then, the patients were brought to the supine position.

The sensory block level was determined with alcohol swabs and a pin-prick test every 2 minutes until no changes were observed in four consecutive tests. The motor block level was determined with a modified Bromage scale [15]. Patients with incomplete spinal anesthesia or a high level of spinal anesthesia (sensory block level > T4) with persistent hypotension (systolic blood pressure $[\mathrm{SBP}]<90 \mathrm{mmHg}$ ) in spite of the treatment with intravenous ephedrine were excluded from the study.

After fixation of the block level of spinal anesthesia, patients were randomly allocated into one of five groups with a variable loading dose of dexmedetomidine; these doses were $0.1,0.3$, $0.5,0.7$, and $1.0 \mu \mathrm{g} / \mathrm{kg}$ for groups I, II, III, IV and V, respectively. Random assignments were made using a sealed envelope method. One vial of dexmedetomidine (Precedex ${ }^{\circledR}$ injection, Hospira, Lake Forest, IL, USA, 2 ml, $200 \mu \mathrm{g}$ ) was mixed with 48 $\mathrm{ml}$ of $0.9 \%$ normal saline and was diluted to $4 \mu \mathrm{g} / \mathrm{ml}$ in a $50 \mathrm{ml}$ syringe. The assigned loading dose for each group was infused over 10 minutes and a maintenance dose was then continued at a rate of $0.3 \mu \mathrm{g} / \mathrm{kg} / \mathrm{h}$ for the next 10 minutes in all groups. Afterwards, the infusion rate for each patient was adjusted at the physician's discretion. Patients were blind to the group to which they were assigned.

The sedation level, vital signs and side effects were assessed prior to spinal anesthesia, prior to the dexmedetomidine loading dose and then every 5 minutes for the following 20 minutes by a researcher blind to the assigned groups. The depth of sedation was determined with the Ramsay sedation scale (RSS) [16], as follows: 1 , anxious and agitated or restless or both; 2 , cooperative, orientated, and tranquil; 3, responds to commands only; 4, brisk response to a light glabellar tap or auditory stimulus; 5 , sluggish response to a light glabellar tap or auditory stimulus; and 6, no response to a light glabellar tap or auditory stimulus. A sedative state with a Ramsay sedation score of 3 or higher was considered as an adequate level of sedation.

The occurrence of hypotension, bradycardia, desaturation $\left(\mathrm{SpO}_{2}<90 \%\right)$, shivering, nausea, and/or vomiting was assessed. Hypotension was defined as a SBP of less than $90 \mathrm{mmHg}$ or a decrease of the blood pressure of more than $30 \%$ compared to baseline values. Hypotension was treated with intravenous fluid and $5 \mathrm{mg}$ of ephedrine. Bradycardia, defined as a HR of less than 
45 beats/min, was treated with an intravenous administration of $0.5 \mathrm{mg}$ of atropine, if necessary.

The results were expressed as the mean $\pm \mathrm{SD}$, median (range) or mean (SE, 95\% confidence intervals [CI]). Statistical analyses were performed using GraphPad Prism version 6.0d for Windows (GraphPad Software, La Jolla, California USA, www. graphpad.com) and R for windows version 3.1 (R Foundation for Statistical Computing, Vienna, Austria. www.R-project.org). A P value of $<0.05$ was considered to be statistically significant.

Logistic regression analysis using a binomial generalized linear model was performed to estimate the effective dose $\left(\mathrm{ED}_{50}\right.$, $\mathrm{ED}_{95}$ ) of dexmedetomidine to induce an adequate level of sedation (RSS $\geq 3$ ) upon the completion of the loading dose $\left(\mathrm{T}_{\mathrm{L}}\right)$ and at 10 minutes thereafter $\left(\mathrm{T}_{\mathrm{L}+10 \mathrm{~min}}\right.$ : the time point when maintenance infusion was done for 10 minutes after the loading dose). The regression coefficients were verified by the t-test of their statistical significance. The fitness for logistic model was verified by the model Chi-square test.

Shapiro-Wilk normality test was used to determine the normal distribution of data. The patients' characteristics were compared among the groups by the Kruskal-Wallis test. Sequential data such as RSS scores and hemodynamic data (SBP, HR and respiratory rate) were compared among the groups by repeated measures ANOVA with Tukey's multiple comparisons as posthoc multiple comparisons. A Fisher's exact test was used to compare the incidence of side effects among groups.

\section{Results}

Fifty eight patients were enrolled in the study. Eleven patients were excluded from the study due to baseline bradycardia, incomplete spinal anesthesia, persistent hypotension, the cancellation of surgery and patient refusal. Forty seven patients complet- ed the study and were included for the statistical analysis. There were no differences among groups in the patients' characteristics or the block level of the spinal anesthesia (Table 1).

Followings are the equations of logistic regression models to estimate the effective loading dose of dexmedetomidine to induce an adequate sedation $\left(\right.$ RSS $\geq 3$ ) at $\mathrm{T}_{\mathrm{L}}$ (Equation 1 ) and at $\mathrm{T}_{\mathrm{L}+10 \mathrm{~min}}$ (Equation 2).

$$
\begin{aligned}
\mathrm{Y}= & 1 /\left(1+\mathrm{e}^{-\mathrm{z}}\right) \text { where, } \mathrm{z}=\mathrm{aX}+\mathrm{b} \\
Z= & -1.524(-3.091 \sim-0.193, P=0.035)+ \\
& 5.201(2.353 \sim 9.028, P=0.002) X \\
\mathrm{Z}= & -2.768(-2.109 \sim-0.427, P=0.02)+ \\
& 14.36(4.594 \sim 24.126, P=0.004) X
\end{aligned}
$$

At the completion of the loading dose for a duration of 10 minutes $\left(\mathrm{T}_{\mathrm{L}}\right)$, the $\mathrm{ED}_{50}$ and $\mathrm{ED}_{95}$ values of the dexmedetomidine loading dose to induce an RSS score that equaled or exceeded 3 were estimated to be $0.29 \mu \mathrm{g} / \mathrm{kg}$ (SE 0.08, 95\% CI 0.14-0.44), and $0.86 \mu \mathrm{g} / \mathrm{kg}$ (SE $0.17,95 \%$ CI $0.52-1.20$ ), respectively. Ten minutes after the completion of the loading dose $\left(\mathrm{T}_{\mathrm{L}+10 \mathrm{~min}}\right)$, the $\mathrm{ED}_{50}$ and $\mathrm{ED}_{95}$ values of the cumulative dose (i.e., sum of the loading dose and the maintenance dose) up to that point to induce a RSS score equal to or greater than 3 were estimated to be $0.24 \mu \mathrm{g} / \mathrm{kg}$ (SE 0.04, 95\% CI 0.20-0.28) and $0.45 \mu \mathrm{g} / \mathrm{kg}$ (SE 0.08, 95\% CI 0.37-0.52), respectively.

RSS scores were higher in groups III, IV and V compared to group I. They were also higher in groups IV and V compared to group II (Table 2). The SBPs and HR decreased significantly during the dexmedetomidine infusion compared to baseline values in all groups except for the heart rates in group I (Table 3). Although there were no differences in vital signs among the groups, hypotension was more frequent in groups IV and $\mathrm{V}(\mathrm{P}=$ 0.013, groups I, II, III vs groups IV, V) (Table 3). No differences were found in the incidence of other side effects among the groups (Table 3).

Table 1. Characteristics of Patients

\begin{tabular}{lccccc}
\hline & $\begin{array}{c}\text { Group I } \\
(\mathrm{n}=9)\end{array}$ & $\begin{array}{c}\text { Group II } \\
(\mathrm{n}=10)\end{array}$ & $\begin{array}{c}\text { Group III } \\
(\mathrm{n}=9)\end{array}$ & $\begin{array}{c}\text { Group IV } \\
(\mathrm{n}=9)\end{array}$ & $\begin{array}{c}\text { Group V } \\
(\mathrm{n}=10)\end{array}$ \\
\hline Sex $(\mathrm{M} / \mathrm{F})$ & $7 / 2$ & $8 / 2$ & $7 / 2$ & $4 / 5$ & $4 / 6$ \\
Age $(\mathrm{yr})$ & $70.8 \pm 5.1$ & $72.4 \pm 5.8$ & $68.0 \pm 3.5$ & $71.8 \pm 5.2$ & $72.9 \pm 6.7$ \\
Weight $(\mathrm{kg})$ & $59.7 \pm 7.2$ & $58.1 \pm 9.5$ & $65.1 \pm 6.4$ & $65.1 \pm 8.5$ & $55.6 \pm 8.2$ \\
Height $(\mathrm{cm})$ & $158.4 \pm 8.4$ & $160.3 \pm 7.3$ & $164.6 \pm 8.9$ & $159.7 \pm 6.8$ & $155.7 \pm 6.9$ \\
Bupivacaine dose (mg) & $9.2 \pm 1.0$ & $9.2 \pm 1.2$ & $9.5 \pm 0.7$ & $9.1 \pm 0.9$ & $9.0 \pm 0.9$ \\
MABL* & & & & T7 (T9-T3) & T8.5 (T11-T5) \\
Cold & T8 (T10-T5) & T6.5 (T10-T4) & T8 (T10-T4) & T10 (T11-T5) & T10.5 (L1-T6) \\
Pinprick & T10 (T12-T6) & T10 (T12-T5) & T10 (T12-T7) & $3(0-3)$ & $3(0-3)$ \\
Motor
\end{tabular}

Values are number of patients or mean \pm SD or median (ranges). Dexmedetomidine loading dose of $0.1,0.3,0.5,0.7$, and $1.0 \mu \mathrm{g} / \mathrm{kg}$ was administered intravenously for 10 minutes in group I, II, III, IV and IV, respectively. In all groups, subsequent maintenance dose was infused at a rate of $0.3 \mu \mathrm{g} / \mathrm{kg} /$ $\mathrm{h}$ for the following 10 minutes. Thereafter, the adjustment of infusion rate was on the discretion of anesthesiologists. ${ }^{*}$ MABL: maximum anesthetic block level. ${ }^{\dagger}$ Motor block level assessed by modified Bromage scale. 
Table 2. Ramsay Sedation Scores

\begin{tabular}{lccccc}
\hline & $\begin{array}{c}\text { Group I } \\
(\mathrm{n}=9)\end{array}$ & $\begin{array}{c}\text { Group II } \\
(\mathrm{n}=10)\end{array}$ & $\begin{array}{c}\text { Group III } \\
(\mathrm{n}=9)\end{array}$ & $\begin{array}{c}\text { Group IV } \\
(\mathrm{n}=9)\end{array}$ & $\begin{array}{c}\mathrm{Group} \mathrm{V}^{+, \neq} \\
(\mathrm{n}=10)\end{array}$ \\
\hline Baseline & $2(1-2)$ & $2(1-2)$ & $1(1-2)$ & $1(1-2)$ & $1(1-2)$ \\
Dex 0 & $2(2-2)$ & $2(2-2)$ & $2(1-2)$ & $2(1-2)$ & $2(2-2)$ \\
Dex 5 & $2(2-3)$ & $2(2-3)$ & $2(2-2)$ & $2(2-3)$ & $2(2-3)$ \\
Dex 10 & $2(2-3)$ & $2.5(2-3)$ & $3(2-4)^{*}$ & $4(3-4)^{*}$ & $3.5(2-5)^{*}$ \\
Dex 15 & $2(2-3)$ & $3(2-4)^{*}$ & $3(2-5)^{*}$ & $5(3-5)^{*}$ & $4(3-6)^{*}$ \\
Dex 20 & $2(2-4)$ & $3(2-4)^{*}$ & $4(3-5)^{*}$ & $5(3-6)^{*}$ & $5(3-6)^{*}$ \\
\hline
\end{tabular}

Values are median (ranges). Dexmedetomidine loading dose of $0.1,0.3,0.5,0.7$, and $1.0 \mu \mathrm{g} / \mathrm{kg}$ was administered intravenously for $10 \mathrm{minutes}$ in group I, II, III, IV and IV, respectively. In all groups, subsequent maintenance dose was infused at a rate of $0.3 \mu \mathrm{g} / \mathrm{kg} / \mathrm{h}$ for the following 10 minutes. Baseline: baseline before spinal anesthesia, Dex 0: immediately before the administration of dexmedetomidine. Dex 5, 10, 15, 20: 5, 10, 15, 20 minutes after the administration of dexmedetomidine. ${ }^{*} \mathrm{P}<0.05$ compared to baseline value. ${ }^{\dagger} \mathrm{P}<0.05$ compared to group I, ${ }^{\dagger} \mathrm{P}<0.05$ compared to group II.

Table 3. Vital Signs and Incidence of Side Effects during Study Period

\begin{tabular}{|c|c|c|c|c|c|c|}
\hline & & $\begin{array}{c}\text { Group I } \\
(\mathrm{n}=9)\end{array}$ & $\begin{array}{l}\text { Group II } \\
(\mathrm{n}=10)\end{array}$ & $\begin{array}{c}\text { Group III } \\
(\mathrm{n}=9)\end{array}$ & $\begin{array}{c}\text { Group IV } \\
(\mathrm{n}=9)\end{array}$ & $\begin{array}{l}\text { Group V } \\
(\mathrm{n}=10)\end{array}$ \\
\hline \multirow[t]{4}{*}{$\mathrm{SBP}(\mathrm{mmHg})$} & Baseline & $145.7 \pm 15.2$ & $139.4 \pm 19.0$ & $144.4 \pm 16.8$ & $147.8 \pm 13.3$ & $140.3 \pm 23.0$ \\
\hline & Dex 0 & $133.2 \pm 14.1$ & $129.7 \pm 20.4$ & $136.2 \pm 14.9$ & $124.8 \pm 15.3^{*}$ & $133.6 \pm 23.1$ \\
\hline & Dex 10 & $132.6 \pm 15.7$ & $125.3 \pm 21.5$ & $138.9 \pm 14.8$ & $138.6 \pm 26.3$ & $133.7 \pm 26.3$ \\
\hline & Dex 20 & $126.8 \pm 17.3^{*}$ & $120.3 \pm 20.5^{*}$ & $129.8 \pm 11.3 *$ & $121.4 \pm 29.3^{*}$ & $122.6 \pm 24.0^{*}$ \\
\hline \multirow[t]{4}{*}{ HR (bpm) } & Baseline & $70.4 \pm 11.1$ & $78.2 \pm 16.0$ & $75.1 \pm 10.3$ & $74.4 \pm 8.3$ & $81.8 \pm 11.4$ \\
\hline & Dex 0 & $77.6 \pm 12.7$ & $82.6 \pm 17.3$ & $79.9 \pm 8.4$ & $76.4 \pm 8.6$ & $84.0 \pm 9.1$ \\
\hline & Dex 10 & $71.8 \pm 11.6$ & $73.6 \pm 13.8$ & $64.4 \pm 9.6^{*}$ & $61.8 \pm 6.3^{*}$ & $66.1 \pm 6.4^{*}$ \\
\hline & Dex 20 & $66.0 \pm 10.0$ & $68.8 \pm 11.2^{*}$ & $63.9 \pm 8.0^{*}$ & $64.0 \pm 7.1^{*}$ & $64.7 \pm 4.2^{*}$ \\
\hline \multirow[t]{4}{*}{ RR (breaths/min) } & Baseline & $15.6 \pm 3.8$ & $17.0 \pm 2.9$ & $14.8 \pm 2.7$ & $15.9 \pm 2.3$ & $16.7 \pm 4.6$ \\
\hline & Dex 0 & $17.6 \pm 3.3$ & $16.5 \pm 3.8$ & $15.7 \pm 3.7$ & $14.9 \pm 2.4$ & $16.2 \pm 3.3$ \\
\hline & Dex 10 & $15.1 \pm 4.6$ & $15.6 \pm 4.4$ & $15.0 \pm 2.6$ & $15.2 \pm 3.2$ & $14.7 \pm 3.9$ \\
\hline & Dex 20 & $17.0 \pm 4.5$ & $14.3 \pm 4.1$ & $16.3 \pm 3.7$ & $13.8 \pm 3.6$ & $15.0 \pm 4.0$ \\
\hline \multicolumn{2}{|c|}{ Bradycardia $(\mathrm{HR}<45 \mathrm{bpm})$} & $0(0 \%)$ & $0(0 \%)$ & $0(0 \%)$ & $0(0 \%)$ & $0(0 \%)$ \\
\hline \multicolumn{2}{|c|}{ Hypotension $^{\dagger}$} & $0(0 \%)$ & $1(10.0 \%)$ & $0(0 \%)$ & $4(44.4 \%)$ & $2(20 \%)$ \\
\hline \multicolumn{2}{|c|}{ Desaturation $\left(\mathrm{SpO}_{2}<90 \%\right)$} & $0(0 \%)$ & $0(0 \%)$ & $1(11.1 \%)$ & $0(0 \%)$ & $0(0 \%)$ \\
\hline \multicolumn{2}{|c|}{ Shivering } & $0(0 \%)$ & $0(0 \%)$ & $0(0 \%)$ & $0(0 \%)$ & $0(0 \%)$ \\
\hline \multicolumn{2}{|l|}{ Nausea/Vomiting } & $0(0 \%)$ & $0(0 \%)$ & $0(0 \%)$ & $0(0 \%)$ & $0(0 \%)$ \\
\hline
\end{tabular}

Values are mean \pm SD or number of patients (\%). Dexmedetomidine loading dose of $0.1,0.3,0.5,0.7$, and $1.0 \mu \mathrm{g} / \mathrm{kg}$ was administered intravenously for 10 minutes in group I, II, III, IV and IV, respectively. In all groups, subsequent maintenance dose was infused at a rate of $0.3 \mu \mathrm{g} / \mathrm{kg} / \mathrm{h}$ for the following 10 minutes. Baseline: baseline before spinal anesthesia, Dex 0: immediately before the administration of dexmedetomidine. Dex 10, 20: 10, 20 minutes after the administration of dexmedetomidine. Hypotension was defined as systolic blood pressure $<90 \mathrm{mmHg}$ or more decreased $30 \%$ than that before spinal anesthesia. ${ }^{*} \mathrm{P}<0.05$ compared to baseline value. ${ }^{\dagger} \mathrm{P}=0.013$ compared between group I, II, III vs group IV, V.

In our study, adequate sedation, defined as an RSS score equal to or greater than 3 , also includes a state of oversedation. When oversedation was defined as an RSS score of 5 or 6 , it was observed in $0(0 \%), 1(10 \%), 3(33 \%), 7$ (78\%), and $6(60 \%)$ patients in groups I, II, III, IV and V, respectively ( $\mathrm{P}=0.02$ between groups I, II versus groups III, IV, and V). The $\mathrm{ED}_{50}$ and $\mathrm{ED}_{95}$ values of cumulative dose until $\mathrm{T}_{\mathrm{L}+10 \min }$ to induce oversedation (RSS score $\geq 5$ ) were also estimated; these values were 0.76 $\mu \mathrm{g} / \mathrm{kg}$ (SE 0.09, 95\% CI 0.67-0.85), and $1.45 \mu \mathrm{g} / \mathrm{kg}$ (SE 0.26, 95\% CI 1.19-1.72), respectively. The effective dose to induce oversedation at TL could not be estimated owing to the low incidence of oversedation until that moment.

\section{Discussion}

In the current study, an appropriate dose of dexmedetomidine for the sedation of elderly patients under spinal anesthesia was determined. The $\mathrm{ED}_{50}$ and $\mathrm{ED}_{95}$ values to induce adequate sedation at the completion of the loading dose $\left(\mathrm{T}_{\mathrm{L}}\right)$ were 0.29 and $0.86 \mu \mathrm{g} / \mathrm{kg}$, respectively. In addition, the $\mathrm{ED}_{50}$ and $\mathrm{ED}_{95}$ values of the cumulative dose at $\mathrm{T}_{\mathrm{L}+10 \mathrm{~min}}$ (sum of the loading dose for a duration of 10 minutes and the maintenance dose for the next 10 minutes) were 0.24 and $0.45 \mu \mathrm{g} / \mathrm{kg}$, respectively. Considering the maintenance infusion rate and duration $(0.3 \mu \mathrm{g} /$ $\mathrm{kg} / \mathrm{h}$ for 10 minutes) in our study, the $\mathrm{ED}_{50}$ and $\mathrm{ED}_{95}$ values of 
the loading dose to induce adequate sedation at $\mathrm{T}_{\mathrm{L}+10 \mathrm{~min}}$ would be about 0.19 and $0.40 \mu \mathrm{g} / \mathrm{kg}$, respectively, as calculated by the subtraction of the maintenance dose for 10 minutes $(0.05 \mu \mathrm{g} / \mathrm{kg})$ from the $\mathrm{ED}_{50}$ and $\mathrm{ED}_{95}$ values of the cumulative dose. Therefore, while the $\mathrm{ED}_{95}$ value to induce sedation within 10 minutes is as high as $0.86 \mu \mathrm{g} / \mathrm{kg}, \mathrm{ED}_{95}$ to induce sedation within $20 \mathrm{~min}$ utes is only $0.40 \mu \mathrm{g} / \mathrm{kg}$ if subsequent infusion at a rate of $0.3 \mu \mathrm{g} /$ $\mathrm{kg} / \mathrm{h}$ is maintained. Moreover, when taking into account the significantly high incidences of hypotension and oversedation with a high loading dose $(\geq 0.7 \mu \mathrm{g} / \mathrm{kg})$ in our study, a loading dose of less than $0.7 \mu \mathrm{g} / \mathrm{kg}$ in geriatric patients is suggested. If a slower onset of sedation is tolerated, a loading dose of $0.4-0.5 \mu \mathrm{g} / \mathrm{kg}$ appears to be appropriate for these patients.

In this study, it is possible that spinal anesthesia affects the sedation status of the patients, which is one of the reasons why this study was designed. However, the sedation effect caused by spinal anesthesia shows a maximal effect 60 minutes after the spinal injection [13]. Therefore, those sedation effects may have more importance during a later period of spinal anesthesia and should therefore be considered when adjusting the maintenance dose of dexmedetomidine. Recently, an optimal maintenance dose of dexmedetomidine during spinal anesthesia was reported in adult patients $[5,17]$. Song et al. [5] showed that maintenance at a rate of $0.25 \mu \mathrm{g} / \mathrm{kg} / \mathrm{h}$ after a loading of $1 \mu \mathrm{g} / \mathrm{kg}$ of dexmedetomidine provided adequate sedation with minimized hemodynamic instability. In another study, dexmedetomidine infusion during spinal anesthesia at a rate as low as $0.2 \mu \mathrm{g} / \mathrm{kg} / \mathrm{h}$ after a loading dose of $1 \mu \mathrm{g} / \mathrm{kg}$ was sufficient to maintain sedation for 90 minutes without delayed recovery [17]. In these studies with high loading dose, a low dose was suggested as appropriate for maintenance infusion. In our study, we used $0.3 \mu \mathrm{g} / \mathrm{kg} / \mathrm{h}$ as a maintenance dose in all groups after the loading dose was completed.

It is known that dexmedetomidine leads to dose-dependent decreases in blood pressure and bradycardia [7,8]. With a high loading dose $(1.0-2.0 \mu \mathrm{g} / \mathrm{kg})$, the blood pressure changes in the biphasic mode; this leads to transient hypertension followed by hypotension. However, when a low loading dose $(0.25-0.50 \mu \mathrm{g} / \mathrm{kg})$ is used, blood pressure changes show a monophasic response of hypotension without precedent hypertension [7]. In our study, although there were no differences among the groups in vital signs, hypotension was observed more frequently in groups IV and $\mathrm{V}$. These findings are in line with the findings of Song et al. [5]. In their study with a fixed loading dose and a variable main- tenance dose of dexmedetomidine, hypotension occurred more frequently with an increase in the dose, whereas the incidence of bradycardia was not dose-related.

There are several limitations of the present study. Because the depth of sedation was assessed during the initial 20 minutes in our study, the dose-response relationship in the later period was not provided. In a study with a dose scheme similar to ours, the peak effect was observed 45 minutes after the initiation of the loading dose while the plasma concentration reached a peak immediately after the completion of the loading dose [18]. In other studies, the maximal sedation effect was reached 30-40 minutes after the dexmedetomidine infusion started [5,17]. Although the maximum sedative effect of dexmedetomidine may not be reflected during the initial 20 minutes of our study, that period is long enough to obtain a target sedation for anxious patients in an operating room. In terms of clinical aspects, we consider that it is desirable to obtain the target effect within 10-20 minutes and then to titrate the dose based on the response of the patient. Accordingly, the estimated effective dose for sedation from the current study would be meaningful for clinical practice. The $\mathrm{ED}_{50}$ and $\mathrm{ED}_{95}$ values causing adequate sedation at $\mathrm{T}_{\mathrm{L}+10 \mathrm{~min}}$ in this study are applicable only when subsequent infusion was maintained at a rate of $0.3 \mu \mathrm{g} / \mathrm{kg} / \mathrm{h}$. With an increase in the maintenance dose, the $\mathrm{ED}_{50}$ and $\mathrm{ED}_{95}$ values at $\mathrm{T}_{\mathrm{L}+10 \mathrm{~min}}$ should be decreased. In addition, the findings of our study are applicable to elderly patients only. Because geriatric patients are considered to be more vulnerable to the adverse effects of sedation, we estimated the effective dose for adequate sedation in this group of patients. As another limitation, the potential differences among groups in sedation depth and vital signs might not be revealed in the statistical analysis because of lack of power related to the small number of patients in each group.

In this study, the effective dose of dexmedetomidine for adequate sedation in elderly patients was estimated, which will be helpful as a guide for choosing the appropriate dose for geriatric patients. With an increase in the loading dose, the target level of sedation will be reached more rapidly but with higher incidence rates of adverse effects.

\section{ORCID}

Sangseok Lee, http://orcid.org/0000-0001-7023-3668

Kye-Min Kim, http://orcid.org/0000-0003-1298-7642

\section{References}

1. Guay J, Choi PT, Suresh S, Albert N, Kopp S, Pace NL. Neuraxial anesthesia for the prevention of postoperative mortality and major morbidity: an overview of cochrane systematic reviews. Anesth Analg 2014; 119: 716-25. 
2. Chery J, Semaan E, Darji S, Briggs WT, Yarmush J, D’Ayala M. Impact of regional versus general anesthesia on the clinical outcomes of patients undergoing major lower extremity amputation. Ann Vasc Surg 2014; 28: 1149-56.

3. Venn RM, Bradshaw CJ, Spencer R, Brealey D, Caudwell E, Naughton C, et al. Preliminary UK experience of dexmedetomidine, a novel agent for postoperative sedation in the intensive care unit. Anaesthesia 1999; 54: 1136-42.

4. Carollo DS, Nossaman BD, Ramadhyani U. Dexmedetomidine: a review of clinical applications. Curr Opin Anaesthesiol 2008; $21: 457-61$.

5. Song J, Kim WM, Lee SH, Yoon MH. Dexmedetomidine for sedation of patients undergoing elective surgery under regional anesthesia. Korean J Anesthesiol 2013; 65: 203-8.

6. Hong JY, Kim WO, Yoon Y, Choi Y, Kim SH, Kil HK. Effects of intravenous dexmedetomidine on low-dose bupivacaine spinal anaesthesia in elderly patients. Acta Anaesthesiol Scand 2012; 56: 382-7.

7. Bloor BC, Ward DS, Belleville JP, Maze M. Effects of intravenous dexmedetomidine in humans. II. Hemodynamic changes. Anesthesiology 1992; 77: 1134-42.

8. Kallio A, Scheinin M, Koulu M, Ponkilainen R, Ruskoaho H, Viinamaki O, et al. Effects of dexmedetomidine, a selective alpha 2-adrenoceptor agonist, on hemodynamic control mechanisms. Clin Pharmacol Ther 1989; 46: 33-42.

9. Precedex ${ }^{(\mathrm{TM})}$ (dexmedetomidine HC injection): prescribing information (online). Available from http://www.accessdata.fda.gov/drugsatfda_ docs/label/2010/021038s017lbl.pdf

10. Lin L, Guo X, Zhang MZ, Qu CJ, Sun Y, Bai J. Pharmacokinetics of dexmedetomidine in Chinese post-surgical intensive care unit patients. Acta Anaesthesiol Scand 2011; 55: 359-67.

11. Välitalo PA, Ahtola-Sätilä T, Wighton A, Sarapohja T, Pohjanjousi P, Garratt C. Population pharmacokinetics of dexmedetomidine in critically ill patients. Clin Drug Investig 2013; 33: 579-87.

12. Iirola T, Ihmsen H, Laitio R, Kentala E, Aantaa R, Kurvinen JP, et al. Population pharmacokinetics of dexmedetomidine during long-term sedation in intensive care patients. Br J Anaesth 2012; 108: 460-8.

13. Pollock JE, Neal JM, Liu SS, Burkhead D, Polissar N. Sedation during spinal anesthesia. Anesthesiology 2000; 93: 728-34.

14. Gentili M, Huu PC, Enel D, Hollande J, Bonnet F. Sedation depends on the level of sensory block induced by spinal anaesthesia. Br J Anaesth 1998; 81: 970-1.

15. Bromage PR. A comparison of the hydrochloride and carbon dioxide salts of lidocaine and prilocaine in epidural analgesia. Acta Anaesthesiol Scand Suppl 1965; 16: 55-69.

16. Ramsay MA, Savege TM, Simpson BR, Goodwin R. Controlled sedation with alphaxalone-alphadolone. Br Med J 1974; 2: 656-9.

17. Ok HG, Baek SH, Baik SW, Kim HK, Shin SW, Kim KH. Optimal dose of dexmedetomidine for sedation during spinal anesthesia. Korean J Anesthesiol 2013; 64: 426-31.

18. Lee S, Kim BH, Lim K, Stalker D, Wisemandle W, Shin SG, et al. Pharmacokinetics and pharmacodynamics of intravenous dexmedetomidine in healthy Korean subjects. J Clin Pharm Ther 2012; 37: 698-703. 